\title{
Postzygotic Isolation Evolves before Prezygotic Isolation between Fresh and Saltwater Populations of the Rainwater Killifish, Lucania parva
}

\author{
Genevieve M. Kozak, ${ }^{1}$ Arthur B. Rudolph, ${ }^{2}$ Beatrice L. Colon, ${ }^{1}$ and Rebecca C. Fuller ${ }^{1}$ \\ ${ }^{1}$ Department of Animal Biology, University of Illinois, Champaign, IL 61820, USA \\ ${ }^{2}$ Department of Biology, University of Florida, Gainesville, FL 32611, USA
}

Correspondence should be addressed to Genevieve M. Kozak, gmkozak@illinois.edu

Received 15 July 2011; Revised 20 September 2011; Accepted 5 October 2011

Academic Editor: Kyoichi Sawamura

Copyright ( $) 2012$ Genevieve M. Kozak et al. This is an open access article distributed under the Creative Commons Attribution License, which permits unrestricted use, distribution, and reproduction in any medium, provided the original work is properly cited.

\begin{abstract}
Divergent natural selection has the potential to drive the evolution of reproductive isolation. The euryhaline killifish Lucania parva has stable populations in both fresh water and salt water. Lucania parva and its sister species, the freshwater L. goodei, are isolated by both prezygotic and postzygotic barriers. To further test whether adaptation to salinity has led to the evolution of these isolating barriers, we tested for incipient reproductive isolation within L. parva by crossing freshwater and saltwater populations. We found no evidence for prezygotic isolation, but reduced hybrid survival indicated that postzygotic isolation existed between $L$. parva populations. Therefore, postzygotic isolation evolved before prezygotic isolation in these ecologically divergent populations. Previous work on these species raised eggs with methylene blue, which acts as a fungicide. We found this fungicide distorts the pattern of postzygotic isolation by increasing fresh water survival in L. parva, masking species/population differences, and underestimating hybrid inviability.
\end{abstract}

\section{Introduction}

There is substantial evidence that adaptation to different environments can lead to the evolution of reproductive isolation between populations, a process referred to as ecological speciation [1-6]. Ecological speciation predicts the evolution of both prezygotic and environmentally dependent postzygotic isolation. Prezygotic isolation can evolve as mating signals and preferences adapt to different environments [7-12]. Extrinsic (environmentally dependent) postzygotic isolation may also evolve since hybrids have intermediate phenotypes and are poorly adapted to parental habitats [13-17]. Currently, there is less evidence that genetic incompatibilities between populations (intrinsic postzygotic isolation) can evolve simply as a consequence of adaptation to different habitats [18-20]. Most identified intrinsic isolating barriers have no clear relationship to adaptation and may have arisen subsequent to ecological divergence [21-23]. However, theoretical and empirical work suggests intrinsic isolation can arise through ecological divergence if there are epistatic interactions between alleles conferring environment-specific adaptations [24-26].

When prezygotic, extrinsic, and intrinsic postzygotic reproductive isolating barriers evolve as byproducts of adaptation, the probability that they will lead to speciation depends on their cumulative strength and ability to persist in the face of gene flow when incipient species come into contact [27]. If the cumulative strength of isolating barriers is insufficient, population divergence will be lost via introgression, and speciation will not occur [28]. Therefore, determining how adaptation generates both pre- and postzygotic isolating barriers and how rapidly these barriers evolve is a key focus of speciation research.

Much previous work has focused on timing and order in which reproductive isolating barriers arise, but has given little consideration to their ecological context. In species of Drosophila studied in a common laboratory environment, prezygotic isolation evolves faster than postzygotic isolation 
$[29,30]$. However, this effect seems to be driven by the effect of sympatry and, in allopatric species, pre- and postzygotic isolation evolve at the same rate. Prezygotic isolation also evolves well before postzygotic isolation in birds [31, 32], salamanders [23], and several groups of fish (including centrarchids [33], African Rift Lake cichlids [34], and darters $[35,36])$. For instance, postzygotic isolation in fish appears to accumulate slowly with hybrid inviability not becoming complete until species have been separated for 10 to 20 million years $[33,34]$. However, in many of these studies, hybrids are raised in a common laboratory environment, which may underestimate hybrid inviability. Differences in population ecology and how these may relate to the strength of isolating barriers are not usually considered. One exception to this is work on stickleback fish which has found that young stickleback species pairs exhibit prezygotic and environmentally based postzygotic isolation, while older pairs show both prezygotic and intrinsic postzygotic isolation $[8,13,37,38]$.

In our study, we ask which reproductive isolating barriers have evolved between ecologically divergent populations within one species of killifish and compare them to barriers that have evolved between two sister species. This allows us to determine the order in which isolating barriers arise as populations adapt to different ecological conditions. The rainwater killifish, Lucania parva, is a euryhaline species with permanent populations existing in fresh, brackish, and salt water across the Southeastern United States [39]. L. parva's sister species, the bluefin killifish (Lucania goodei), is found almost exclusively in fresh water in Florida [40]. Sympatric populations of L. parva and L. goodei can be found in several freshwater sites across Florida. Multiple lines of evidence suggest that adaptation to different salinity conditions has occurred between species. L. goodei has higher fitness in fresh water relative to L. parva, and L. parva fares better in brackish and salt water than L. goodei [41]. Additionally, L. goodei has a decreased rate of hatching success at high salinities while $L$. parva has a lower rate of survival to adulthood in fresh water [41-43]. However, L. parva appears to have equal hatching success with L. goodei in fresh water. All this previous work on L. parva and L. goodei has raised eggs with the fungicide methylene blue [44]. While this fungicide improves hatching success, it may do so disproportionally for different salinities, populations, or species. Therefore, in our study, we raised eggs in water with and without methylene blue.

Reproductive isolation between L. parva and L. goodei involves both prezygotic and postzygotic barriers. Behavioral isolation is quite strong with L. parva and L. goodei mating pairs taking longer to produce eggs than conspecific pairs and producing fewer eggs [41]. Postzygotic isolation between species is both extrinsic and intrinsic. Backcrosses, F1, and F2 hybrids have reduced survival, particularly at high salinities. In addition, F1 hybrids sons of L. parva females and L. goodei males have reduced fertility [43].

Some of these isolating barriers between L. parva and L. goodei may have arisen due simply to adaptation to fresh and salt water. Life in fresh water and salt water pose different osmoregulatory challenges for aquatic animals. In fresh water, fish need to keep excess water out of their bodies,

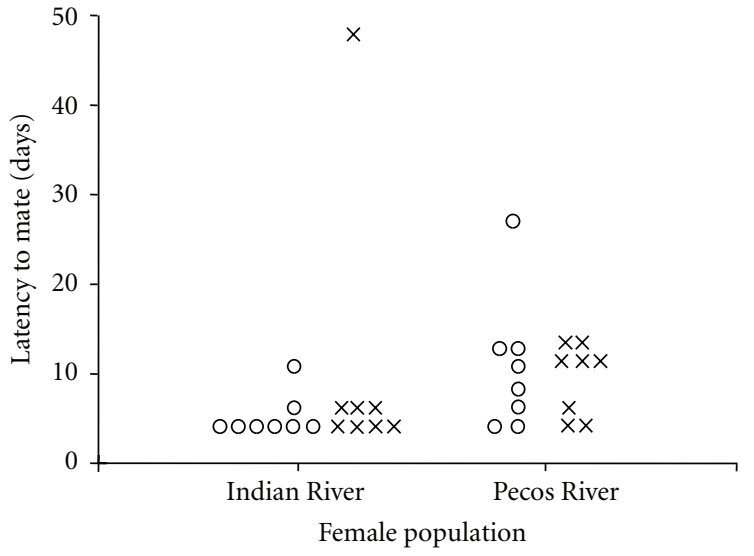

(a)

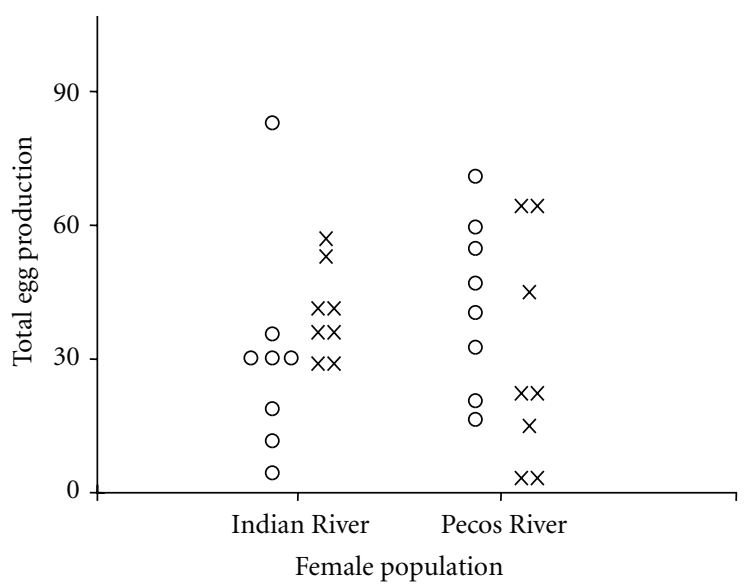

Male populatio
$\times$ Pecos River
- Indian River

(b)

Figure 1: L. parva mate preference. Measures of behavioral isolation between populations plotted by female source population. Circles indicate females mated to Indian River males, crosses indicate females mated to Pecos River males. (a) Latency to mate in days (including outlier), (b) total egg production over 61 days.

while retaining vital salts. However, marine fish need to extricate salt, but retain water [45]. Throughout the life of the fish, osmoregulation can occur in the gills, guts, kidneys, and skin [46]. Therefore, adaptation to salinity can potentially cause divergence in many genes involved in ion regulation $[47,48]$, increasing the likelihood of speciation as a direct consequence of adaptation to salinity [5]. To ask how salinity may drive the evolution of isolation barriers in Lucania, we measured isolation between L. parva populations adapted to different salinity environments.

We collected L. parva from a permanent fresh water population (Pecos River) and a salt water population (Indian River Lagoon). We crossed Pecos and Indian River fish and predicted that if prezygotic isolation existed, between populations, mating pairs would take longer to mate and produce fewer eggs than within population pairs. We 


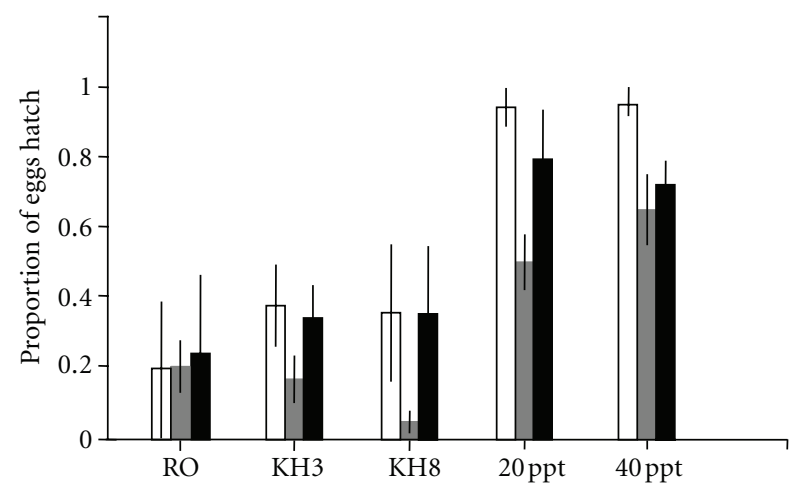

(a)

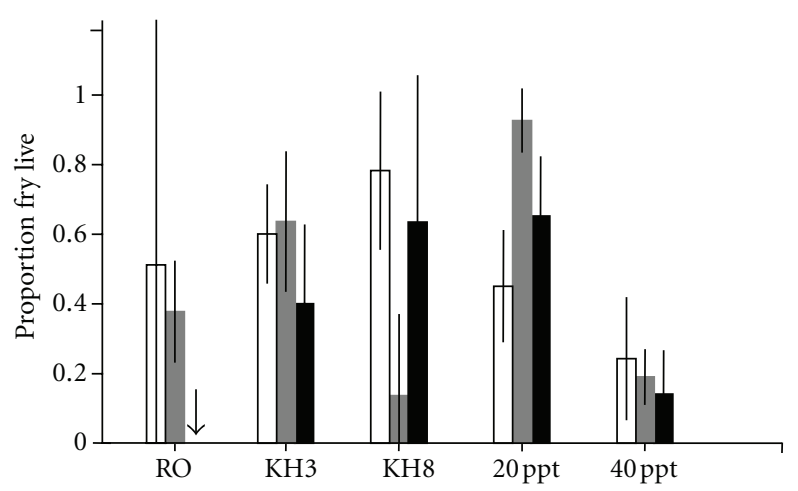

(b)

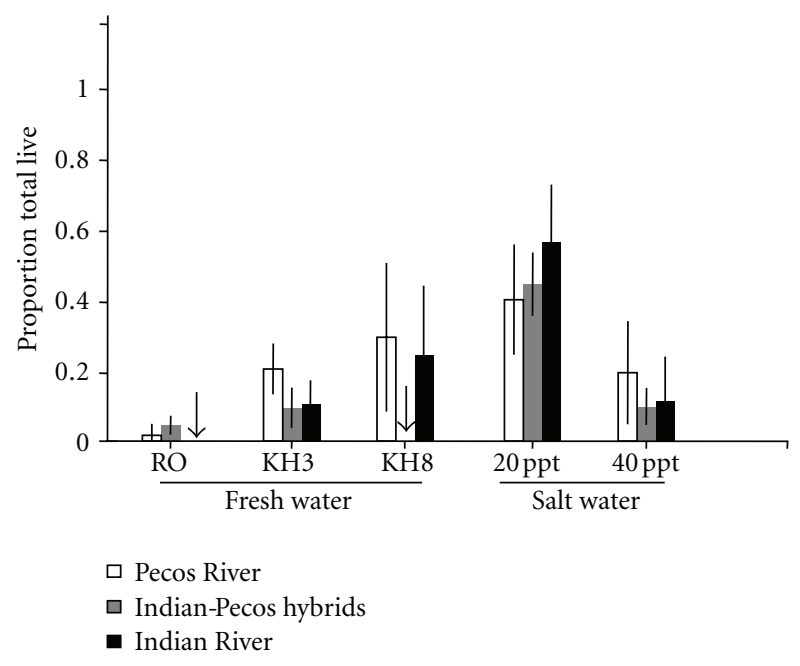

(c)

Figure 2: L. parva survival differences in fresh and salt water. Mean survival probabilities ( \pm standard error) for Pecos River (white bars), Indian River (black bars), and Indian-Pecos hybrid crosses (gray bars) across different water chemistries: reverse osmosis water (RO), soft water (KH3), hard water (KH8), saline (20 ppt), and hypersaline (40 ppt). All crosses were raised in the absence of methylene blue. Arrows indicate mean survival probability of zero. (a) The proportion of eggs hatched, (b) proportion of fry that survived to 14 days after hatch, (c) total survival (proportion of eggs that survived to 14 days after hatch).

then raised Pecos-Indian River hybrid eggs in five water chemistries ranging from fresh to salt water and measured survival. If postzygotic isolation exists, hybrid eggs and fry should have lower survival than either of the parental populations. Hybrid inviability across environments would be evidence for intrinsic isolation, while environmentally dependent inviability would suggest that isolation is extrinsic. Furthermore, if any local adaptation is present, we would predict the freshwater population to have higher survival than the saltwater population in fresh water treatments and the saltwater population to have higher survival in salt water conditions. We measured survival of our L. parva populations with and without methylene blue to determine if the fungicide had any effect on measures of postzygotic isolation.

Additionally, we wished to compare the survival of freshwater, saltwater, and hybrid L. parva to $L$. goodei survival. Previous work has established that $L$. goodei has extremely low survival in salt water, but equal survival with L. parva in fresh water. However, in these studies, eggs were raised in methylene blue, and only a single fresh water treatment was used [39]. Therefore, we collected eggs from one population of $L$. goodei and raised them in two fresh water treatments in the absence of methylene blue. We predicted that L. goodei should have higher survival in fresh water than L. parva.

\section{Methods}

We collected $L$. parva from two ecologically different and geographically distant sites: an inland river in Texas and the Atlantic Ocean off the coast of Florida. Our freshwater site was Pecos River, along the Pecos-Crockett County border, TX. At the time of collection, the carbonate hardness $(\mathrm{KH}$, a measure of mineral content) of the water was low (between 3 and 4). However, the upper Pecos River does have a history of salinization due to input from salt springs and dam construction altering water flow, which may contribute to $L$. parva's persistence there [49]. Our saltwater site was Indian River Lagoon, Brevard County, FL, on the Atlantic 
TABLE 1: Analyses of prezygotic isolation between L. parva populations. Results of general linear model for (a) latency to mate, (b) total number of eggs produced. Male population (Pecos, Indian River), female population (Pecos, Indian River), and their interaction are included as factors. Prezygotic isolation predicts an interaction between male population and female population. Statistically significant values are indicated in bold.

(a) Latency to mate

\begin{tabular}{lcccccc}
\hline & \multicolumn{3}{c}{ Outlier included } & \multicolumn{3}{c}{ Outlier removed } \\
Source & $d f$ & $F$ & $P$ & $d f$ & $F$ & $P$ \\
\hline Male population & 1,28 & 0.32 & 0.58 & 1,27 & 0.34 & 0.56 \\
$\begin{array}{l}\text { Female population } \\
\begin{array}{l}\text { Male * Female } \\
\text { population }\end{array}\end{array}$ & 1,28 & 0.52 & 0.48 & $\mathbf{1 , 2 7}$ & $\mathbf{9 . 3 1}$ & $\mathbf{0 . 0 0 5 1}$ \\
\hline
\end{tabular}

(b) Total number of eggs produced

\begin{tabular}{lccc}
\hline Source & $d f$ & $F$ & $P$ \\
\hline Male population & 1,28 & 0.08 & 0.78 \\
$\begin{array}{l}\text { Female population } \\
\begin{array}{l}\text { Male } * \text { Female } \\
\text { population }\end{array}\end{array}$ & 1,28 & $<0.01$ & 0.96 \\
\hline
\end{tabular}

coast. Salinity in Indian River is typically $35 \mathrm{ppt}$. We collected L. goodei from the Wakulla River, Wakulla County, FL. At each site, we collected animals using dipnets and seines. The collected fish were transported back to University of Illinois and housed in 75-109 L stock tanks. Indian River (IR) fish were kept in reverse osmosis water raised to $35 \mathrm{ppt}$ salinity using Instant Ocean Sea Salt (Spectrum Brands, Atlanta, GA). They were then transitioned to $10 \mathrm{ppt}$ water, then at the beginning of the experiment to tanks containing city water treated with the dechlorinating agent Start Right (Jungle Laboratories, Cibolo, TX) at 2 ppt salinity. Pecos River fish were kept in treated city water at 2 ppt salinity and with Alkaline Regulator (Seachem, Madison, GA) added to bring the carbonate hardness $(\mathrm{KH})$ to 10 . Fish were fed daily ad libitum with a mixture of frozen brine shrimp and flake food. Fish were maintained under a light cycle of 14 hours light, 10 hours dark.

We performed both within and between population crosses. We set up four different cross types: two within population crosses (Pecos female by Pecos male, IR female by IR male) and two between population crosses (Pecos female by IR male, IR female by Pecos male). There were 8 replicates of each cross type, for a total of 32 pairings. For each pair, we placed one male and one female in a $38 \mathrm{~L}$ tank filled with dechlorinated city water at $2 \mathrm{ppt}$ salinity. Visual barriers were placed between all tanks to isolate mating pairs from others. Four yarn mops were provided as a spawning substrate (two floating and two sinking mops).

The mops were checked for eggs every 2-3 days. All collected eggs were checked under a microscope to verify that they were recently fertilized. Killifish eggs take approximately 7-9 days to hatch; therefore, most eggs (at 1-2 days old) were very early in development when they were transferred to their water treatments. We recorded the number of eggs found on
TABLe 2: Analyses of L. parva survival based on cross type (Pecos, IR, Hybrid) and water chemistry. Results of generalized linear model for (a) proportion of eggs hatched, (b) proportion of fry that survived to 14 days after hatch, (c) total survival (proportion of eggs that survived to 14 days after hatch) in five different water chemistries: reverse osmosis water (RO), soft water (KH3), hard water (KH8), saline (20 ppt), and hypersaline (40 ppt). Statistically significant values are indicated in bold. Number of families per water treatment: $\mathrm{RO}=22, \mathrm{KH} 3=25, \mathrm{KH} 8=25,20 \mathrm{ppt}=25,40 \mathrm{ppt}$ $=24$; total $=121$. Number of eggs per water treatment: $\mathrm{RO}=220$, $\mathrm{KH} 3=241, \mathrm{KH} 8=224,20 \mathrm{ppt}=326,40 \mathrm{ppt}=241$. Number of fry per water treatment: $\mathrm{RO}=39, \mathrm{KH} 3=66, \mathrm{KH} 8=44,20 \mathrm{ppt}=242$, $40 \mathrm{ppt}=181$.

(a) Proportion of eggs hatched

\begin{tabular}{lccc}
\hline Source & $d f$ & $\chi^{2}$ & $P$ \\
\hline Cross & $\mathbf{2}$ & $\mathbf{1 8 . 8 3}$ & $<\mathbf{0 . 0 0 0 1}$ \\
Water Chemistry & $\mathbf{4}$ & $\mathbf{1 0 6 . 4 8}$ & $<\mathbf{0 . 0 0 0 1}$ \\
Cross $*$ Water Chemistry & 8 & 8.23 & 0.4116 \\
\hline
\end{tabular}

(b) Proportion of fry survive

\begin{tabular}{lccc}
\hline Source & $d f$ & $\chi^{2}$ & $P$ \\
\hline Cross & 2 & 0.64 & 0.7257 \\
Water Chemistry & $\mathbf{4}$ & $\mathbf{5 9 . 7 3}$ & $<\mathbf{0 . 0 0 0 1}$ \\
Cross $*$ Water Chemistry & $\mathbf{8}$ & $\mathbf{2 4 . 7 7}$ & $\mathbf{0 . 0 0 1 7}$ \\
\hline
\end{tabular}

(c) Total survival

\begin{tabular}{lccc}
\hline Source & $d f$ & $\chi^{2}$ & $P$ \\
\hline Cross & 2 & 1.83 & 0.4013 \\
Water Chemistry & $\mathbf{4}$ & $\mathbf{7 7 . 4 7}$ & $<\mathbf{0 . 0 0 0 1}$ \\
Cross $*$ Water Chemistry & $\mathbf{8}$ & $\mathbf{1 9 . 9 0}$ & $\mathbf{0 . 0 1 0 7}$ \\
\hline
\end{tabular}

each egg check. Latency to mate was measured over the first 47 days and was calculated as the number of days until the first egg was found. If a pair had not mated after 47 days, we assigned them a latency of 48 days (the total number of days plus 1 day) [41]. After 47 days, we removed visual barriers between tanks to encourage spawning and continued collecting eggs. We summed the total number of eggs laid over the entire experiment (61 days).

Eggs were transferred to small plastic tubs with different water treatments. There were three fresh water treatments: pure reverse osmosis water (RO), soft water (KH3), and hard water (KH8). The RO water was created using a filtration system that removes sediment, chlorine, and other large ions from city water (AquaFx Barracuda 4 Stage RO/DI System, Winter Park, FL). Soft water was created by adding Alkaline Regulator (Seachem, Madison, GA) and R/O Right (Kent Marine, Franklin, WI) to adjust the ionic content of $\mathrm{RO}$ water to a carbonate hardness of $\mathrm{KH} 3$. Hard water was created by adding Alkaline Regulator and R/O Right to dechlorinated city water until its hardness was KH8. The salt water treatments were made by adding Instant Ocean Sea Salt to $\mathrm{RO}$ water until the desired salinity was reached. Ocean water is typically $32 \mathrm{ppt}$, and we used two salinity treatments: saline $(20 \mathrm{ppt})$ and hypersaline $(40 \mathrm{ppt})$. Additionally, we raised some eggs in the $\mathrm{KH} 8$ and 20 ppt treatments with 


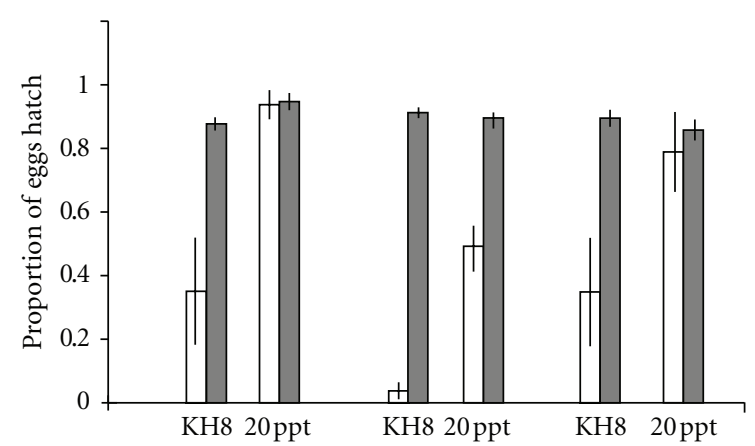

(a)

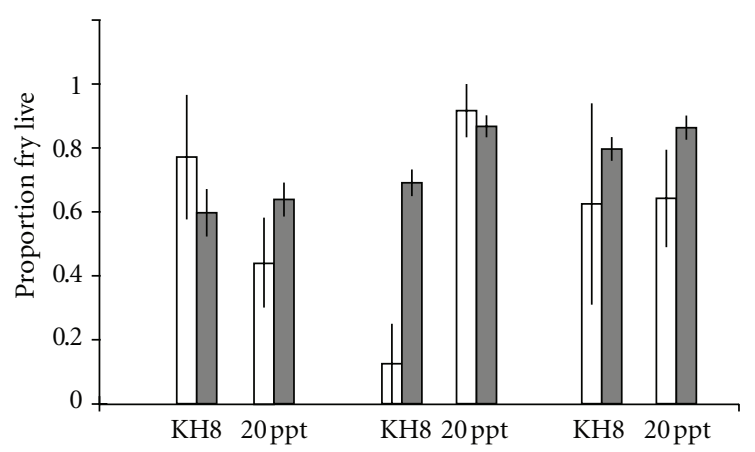

(b)

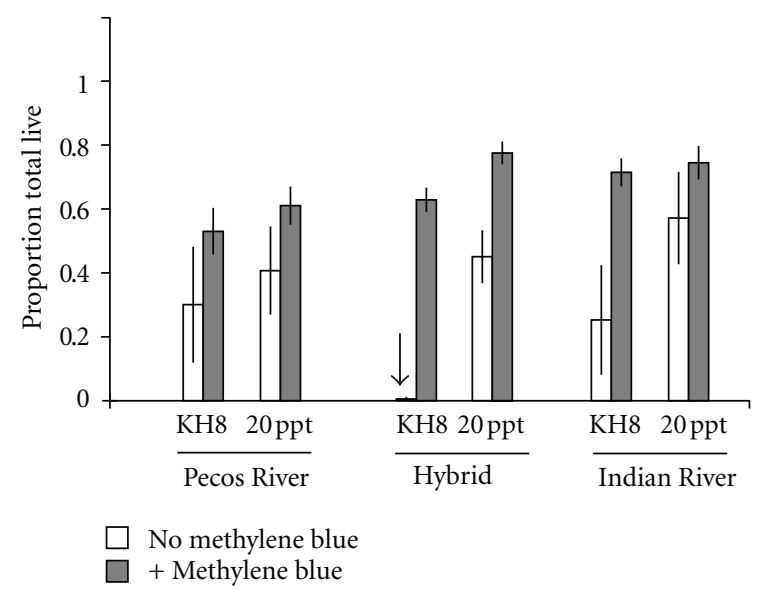

(c)

Figure 3: L. parva survival differences with methylene blue addition. Mean survival probabilities ( \pm standard error) for Pecos River, Indian River, and Indian-Pecos hybrid crosses in fresh water (KH8) and salt water (20 ppt) with methylene blue addition (gray bars) and without (white bars). Arrows indicate mean survival probability of zero. (a) The proportion of eggs hatched, (b) proportion of fry that survived to 14 days after hatch, (c) total survival (proportion of eggs that survived to 14 days after hatch).

methylene blue, the antifungal agent. A 3 ppm solution of methylene blue $\left(\mathrm{C}_{16} \mathrm{H}_{18} \mathrm{~N}_{3} \mathrm{SCl}\right.$; Kordon LLC, Hayward, CA) was added to the water immediately after eggs were placed in it. We rotated the water treatment every egg collection day to assure an equal distribution of eggs in each water treatment. We collected eggs until each water treatment had at least 10 eggs from each tank. Once the eggs hatched, we transferred the fry into clean tubs with the same water treatments.

Eggs and fry were censused every 2-3 days. We recorded the number of eggs that were alive or dead, the number of eggs hatched, and the number of fry that were alive or dead. These censuses continued until 14 days after hatching, at which point fry were euthanized with an overdose of MS222. We measured survival in several ways. We measured the proportion of eggs that hatched (hatching success), the proportion of fry that survived to 14 days of age (fry survival), and the proportion of eggs that produced surviving fry of 14 days of age (total survival). These proportions were calculated separately for each family in each water chemistry. We combined the data for the two between population cross types into one hybrid group. We had eggs from 32 families total $($ Pecos $=8, I R=8$, Hybrid $=16)$. Not all families had eggs in all water chemistries; therefore, we list sample sizes for each water chemistry in our table legends.
To measure L. goodei survival in fresh water in the absence of methylene blue, we collected eggs from L. goodei stock tanks (not from the preestablished crosses). Mops from these tanks were checked three times a week. The eggs collected were placed into $\mathrm{KH} 3$ or $\mathrm{KH} 8$ treatments, both without methylene blue. These eggs were also checked under a microscope to verify they were fertilized. Hatching success and fry survival were measured as described above.

All statistical analyses were performed using SAS statistical software (SAS V 9.1, Cary, NC). Measures of prezygotic isolation (latency to mate and total number of eggs produced) were analyzed in a general linear model with male source population (Pecos, Indian River), female source population (Pecos, Indian River), and the interaction between male population and female population. If behavioral isolation existed, we would expect a significant interaction between male and female population. There was an outlier in our latency to mate data, with one Indian River female by Pecos male taking more than 47 days to mate, so we performed the analysis with and without this outlier to determine if it affected our conclusions.

For survival data, we analyzed the proportion surviving at each life stage for each cross type using generalized linear models assuming a binomial distribution (proc genmod 
in SAS) and used maximum likelihood to evaluate the significance of effects. We used the "dscale" option in SAS to control for overdispersion when this occurred [43]. To determine survival in the absence of methylene blue, we used a model that considered the effects of water chemistry (RO, KH3, KH8, 20 ppt, 40 ppt), cross type (Pecos, IR, Hybrid), and their interaction on the probability of hatching, fry survival, and total survival. We also ran analyses where we included family (nested within cross type) as a repeated factor in our general linear model, but it did not alter our results, and these analyses are not presented here.

To determine the effects of methylene blue on survival in hard and $20 \mathrm{ppt}$, we ran a second model which examined the effects of cross type, water chemistry (KH8, $20 \mathrm{ppt}$ ), presence/absence of methylene blue and their interactions on the probability of hatching, fry survival, and total survival.

To compare L. parva to L. goodei fresh water survival in the absence of methylene blue, we analyzed probability of survival at each stage (egg, fry, total) in fresh water chemistries (KH3, KH8), based on cross type (Pecos, IR, Hybrid, L. goodei) and included the interaction between cross type and water chemistry. Means and standard errors are reported throughout for all analyses.

\section{Results}

We found no evidence for prezygotic isolation between Pecos and Indian River fish. Between populations pairs (Pecos male by Indian River female; Indian River male by Pecos female) did not differ from within population pairs in latency to mate or total number of eggs produced (Table 1; Figure 1). Removal of the latency outlier did not alter our conclusions about prezygotic isolation. However, when the outlier was removed, we found there was a difference in latency to mate between female populations with Indian River females mating sooner than Pecos females ( IR $=5.00 \pm 1.89$ days, Pecos $=9.94 \pm 5.82$ days $)$.

Despite a lack of prezygotic isolation, we found that offspring from Pecos-Indian River hybrid crosses had reduced survival. Hybrid eggs had lower hatching success than within population eggs across different water treatments (Table 2(a), Figure 2(a)). The proportion of fry that lived and total survival were also lower for hybrid crosses, but only in hard water (Tables 2(b) and 2(c); Figures 2(b) and 2(c); significant cross by water treatment interaction). However, no reduction in hybrid hatching rates was detected when methylene blue was added to the water treatments (Table 3, Figure 3; significant methylene blue by cross interaction). When methylene blue was present, hybrid offspring survived quite well. There was little evidence for local adaptation in egg and fry survival as we did not detect consistent differences between Pecos and Indian River survival. In both populations, hatching success was higher in salt water than in fresh water.

L. goodei eggs hatched more than L. parva eggs in fresh water treatments in the absence of methylene blue (Table 4; Figure 4). Total survival of $L$. goodei eggs and fry was also higher than $L$. parva survival in fresh water. These differences
TABLE 3: Analyses of L. parva survival in the presence or absence of methylene blue (MB) for hard water (KH8) and salt water (20 ppt). Results of generalized linear model for (a) proportion of eggs hatched, (b) proportion of fry that survived to 14 days after hatch, (c) total survival (proportion of eggs that survived to 14 days after hatch). Statistically significant values are indicated in bold. Number of families per water treatment: without MB KH8 $=25,20 \mathrm{ppt}=$ 25 , with $\mathrm{MB} \mathrm{KH} 8=32,20 \mathrm{ppt}=32$; total $=114$. Number of eggs per water treatment: without $\mathrm{MB} \mathrm{KH} 8=224,20 \mathrm{ppt}=326$, with $\mathrm{MB} \mathrm{KH} 8=1255,20 \mathrm{ppt}=1019$. Number of fry per water treatment: without MB KH8 = 44, 20 ppt $=242$, with MB KH8 $=1129,20$ ppt $=908$.

(a) Proportion of eggs hatched

\begin{tabular}{lccc}
\hline Source & $d f$ & $\chi^{2}$ & $P$ \\
\hline$M B$ & $\mathbf{1}$ & $\mathbf{5 1 . 9 1}$ & $<\mathbf{0 . 0 0 0 1}$ \\
Water Chemistry & $\mathbf{1}$ & $\mathbf{3 5 . 4 5}$ & $<\mathbf{0 . 0 0 0 1}$ \\
$M B *$ Water Chemistry & $\mathbf{1}$ & $\mathbf{2 9 . 8 0}$ & $<\mathbf{0 . 0 0 0 1}$ \\
Cross & $\mathbf{2}$ & $\mathbf{4 . 2 7}$ & $\mathbf{0 . 0 1 4}$ \\
$M B *$ Cross & $\mathbf{2}$ & $\mathbf{5 . 3 9}$ & $\mathbf{0 . 0 0 4 5}$ \\
Water Chemistry $*$ Cross & 2 & 2.02 & 0.1325 \\
MB $*$ Water Chemistry $*$ Cross & 2 & 0.13 & 0.8821 \\
\hline
\end{tabular}

(b) Proportion of fry survive

\begin{tabular}{lccc}
\hline Source & $d f$ & $\chi^{2}$ & $P$ \\
\hline MB & 1 & 0 & 0.9574 \\
Water Chemistry & 1 & 1.41 & 0.2357 \\
MB $*$ Water Chemistry & 1 & 0.12 & 0.7278 \\
Cross & 2 & 0.96 & 0.3828 \\
MB $*$ Cross & 2 & 0.07 & 0.9285 \\
Water Chemistry $*$ Cross & $\mathbf{2}$ & $\mathbf{7 . 0 6}$ & $\mathbf{0 . 0 0 0 9}$ \\
MB $*$ Water Chemistry $*$ Cross & $\mathbf{2}$ & $\mathbf{4 . 5 8}$ & $\mathbf{0 . 0 1 0 3}$ \\
\hline
\end{tabular}

(c) Total survival

\begin{tabular}{lccc}
\hline Source & $d f$ & $\chi^{2}$ & $P$ \\
\hline$M B$ & $\mathbf{1}$ & $\mathbf{5 6 . 5 5}$ & $<\mathbf{0 . 0 0 0 1}$ \\
Water Chemistry & $\mathbf{1}$ & $\mathbf{2 2 . 2 7}$ & $<\mathbf{0 . 0 0 0 1}$ \\
MB $*$ Water Chemistry & $\mathbf{1}$ & $\mathbf{1 2 . 0 4}$ & $\mathbf{0 . 0 0 0 5}$ \\
Cross & 2 & 2.74 & 0.0644 \\
MB $*$ Cross & 2 & 2.85 & 0.0578 \\
Water Chemistry $*$ Cross & $\mathbf{2}$ & $\mathbf{4 . 3 1}$ & $\mathbf{0 . 0 1 3 5}$ \\
MB $*$ Water Chemistry $*$ Cross & 2 & 2.67 & 0.0692 \\
\hline
\end{tabular}

seem primarily driven by high survival of $L$. goodei eggs and fry in soft water treatments. These results are in contrast to previous work that found no difference between the species when methylene blue was used.

\section{Discussion}

Here, we show that postzygotic isolation has begun to evolve between freshwater and saltwater populations of $L$. parva. However, there is no evidence that any prezygotic isolation yet exists. This suggests that genes involved in hatching success and fry survival evolve more rapidly between 
TABle 4: Analyses of L. goodei and L. parva survival in two fresh water chemistries (KH3 and KH8). Results of generalized linear model for (a) proportion of eggs hatched, (b) proportion of fry that survived to 14 days after hatch, (c) total survival (proportion of eggs that survived to 14 days after hatch). Statistically significant values are indicated in bold. Number of families per water treatment: IR $\mathrm{KH} 3=6, \mathrm{KH} 8$ = 6; Hybrid $\mathrm{KH} 3=13, \mathrm{KH} 8=14 ;$ Pecos $\mathrm{KH} 3=6$, $\mathrm{KH} 8=5 ;$ L. goodei $\mathrm{KH} 3=5, \mathrm{KH} 8=7$; total $=62$. Number of eggs per water treatment: IR KH3 $=79, \mathrm{KH} 8=78$; Hybrid $\mathrm{KH} 3=94$, $\mathrm{KH} 8=86$; Pecos KH3 = 68, KH8 = 60; L. goodei $\mathrm{KH} 3=50, \mathrm{KH} 8$ $=31$. Number of fry per water treatment: IR KH3 = 21, KH8 = 21; Hybrid KH3 = 14, KH8 = 7; Pecos KH3 = 31, KH8 = 16; L. goodei $\mathrm{KH} 3=45, \mathrm{KH} 8=13$.

(a) Proportion of eggs hatched

\begin{tabular}{lccc}
\hline Source & $d f$ & $\chi^{2}$ & $P$ \\
\hline Cross & $\mathbf{3}$ & $\mathbf{2 7 . 9 4}$ & $<\mathbf{0 . 0 0 0 1}$ \\
Water Chemistry & $\mathbf{1}$ & $\mathbf{7 . 2 6}$ & $\mathbf{0 . 0 0 7 0}$ \\
Cross $*$ Water Chemistry & 3 & 5.38 & 0.1452 \\
\hline
\end{tabular}

(b) Proportion of fry survive

\begin{tabular}{llcr}
\hline Source & $d f$ & $\chi^{2}$ & $P$ \\
\hline Cross & 3 & 4.02 & 0.2592 \\
Water Chemistry & 1 & 0.62 & 0.4302 \\
Cross $*$ Water Chemistry & 3 & 6.47 & 0.0908 \\
\hline
\end{tabular}

(c) Total survival

\begin{tabular}{lccr}
\hline Source & $d f$ & $\chi^{2}$ & $P$ \\
\hline Cross & $\mathbf{3}$ & $\mathbf{9 . 4 8}$ & $<\mathbf{0 . 0 0 0 1}$ \\
Water Chemistry & 1 & 1.53 & 0.2162 \\
Cross $*$ Water Chemistry & $\mathbf{3}$ & $\mathbf{3 . 2 5}$ & $\mathbf{0 . 0 2 0 9}$ \\
\hline
\end{tabular}

L. parva populations than genes involved in mating traits and preferences. Most previous work suggests that pre- and postzygotic isolation evolve at similar rates in allopatric populations $[29,30]$, but this does not appear to be true in $L$. parva.

When we examined population differences within $L$. parva, we found that F1 hybrids between freshwater and saltwater populations had reduced survival compared to offspring from within population crosses. These effects were most apparent in challenging water chemistries: in fresh water and in the absence of methylene blue. The most drastic reduction of hybrid survival was in hard water (KH8). The lethality of hard water may be due to fungus that grew readily in this water treatment. Fungal infections are a major source of egg mortality and both high salinity and methylene blue can prevent infection, although methylene blue is more effective $[44,50]$. Methylene blue may also add ions to the water, which may decrease osmoregulatory stress and may be why methylene blue also increased fry survival at low salinities. This suggests that hybrid eggs were less viable than eggs from within population crosses and physiologically challenging water chemistries revealed this decreased viability. We also showed that $L$. parva has lower survival compared to L. goodei in fresh water in the absence of methylene blue. This contradicts previously published results that used methylene blue and found no difference in fresh water survival between species [41-43]. This suggests that F1 hybrids between $L$. goodei and L. parva may also have low survival in fresh water, but these effects have been masked by the use of methylene blue in previous studies and hybrid fitness may have been previously overestimated.

The decreased viability of Pecos and Indian River hybrid offspring suggests that intrinsic postzygotic isolation exists between populations. The main difference between Pecos and Indian River populations is their native salinity, suggesting that genetic incompatibilities have arisen as a byproduct of adaptation to saline environments. However, in allopatric populations, any mechanism which causes unique alleles to become fixed has the potential to cause incompatibilities as novel alleles come into contact and interact in hybrids (Dobzhansky-Muller incompatibilities: [18, 51-53]). Intrinsic postzygotic isolation between populations can also arise due to genetic drift $[20,52,54]$ or genomic conflict [55]. Pecos and Indian River are geographically distant, separated by more than $2400 \mathrm{~km}$ and the Gulf of Mexico. Work on other related species from the Fundulus clade has found substantial divergence between east and west Gulf populations, possibly due to genetic drift [56]. Therefore, we are currently working on determining the degree of genetic divergence and phylogenetic relationship between these populations using sequence data. In addition, we are conducting crosses between other ecologically divergent populations from the same geographical region as well as geographically distant but ecologically similar populations. This ongoing work will determine if hybrid inviablity in $L$. parva evolves primarily due to salinity adaptation rather than due to drift.

How isolation arises during the initial stages of speciation, when a single population splits into two and populations begin to diverge, still represents a "missing link" in speciation research [57]. By showing that intrinsic postzygotic isolation has begun to evolve between divergent $L$. parva populations, our work suggests it may have been the first barrier to arise between L. parva and its sister species L. goodei. Adaption to salinity is primarily physiological and, therefore, may be particularly likely to cause intrinsic isolation through epistatic interactions. Similarly, physiological changes associated with toxic environments also appear to lead to substantial genetic changes between populations and, in some cases, to hybrid inviability [58-61]. Therefore, physiological adaptation may be a primary force leading to postzygotic incompatibilities.

Currently, there are competing ideas about how isolating barriers evolve during speciation. In one proposed scenario, strong prezygotic isolation evolves before strong postzygotic isolation. Thus, prezygotic isolation plays a primary role in preventing interbreeding, and postzygotic isolation slowly completes the process of speciation as decreased hybrid fitness and irreversible genetic incompatibilities accumulate $[28,62,63]$. However, this conclusion is based on studies of species pairs that have already undergone speciation $[29,34,35]$, populations that occur in sympatry where reinforcement may have strengthened prezygotic isolation $[30,64,65]$, or populations in which feeding and mating 


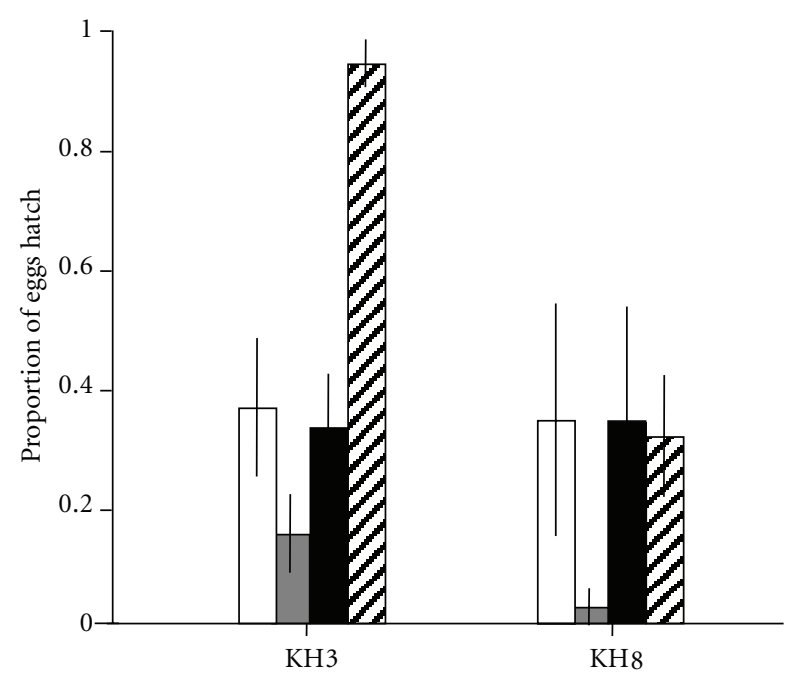

(a)

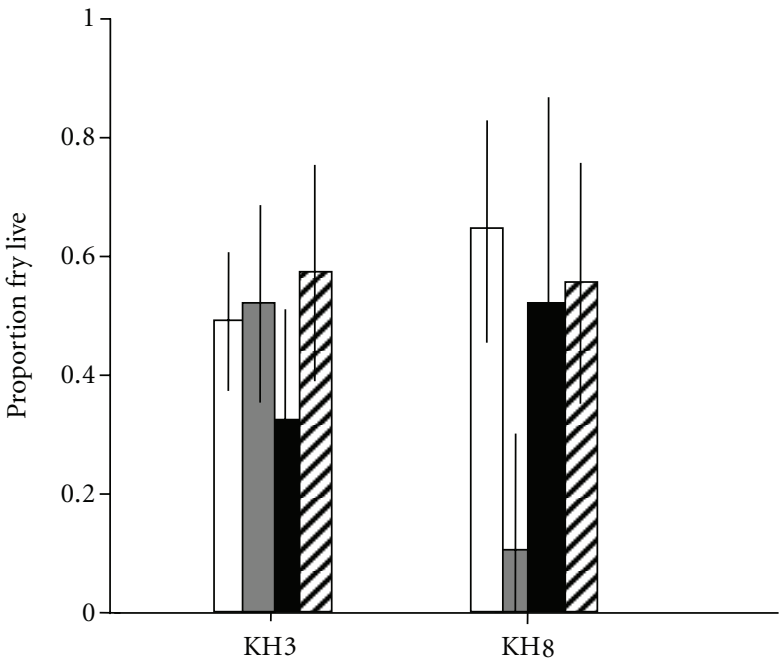

(b)

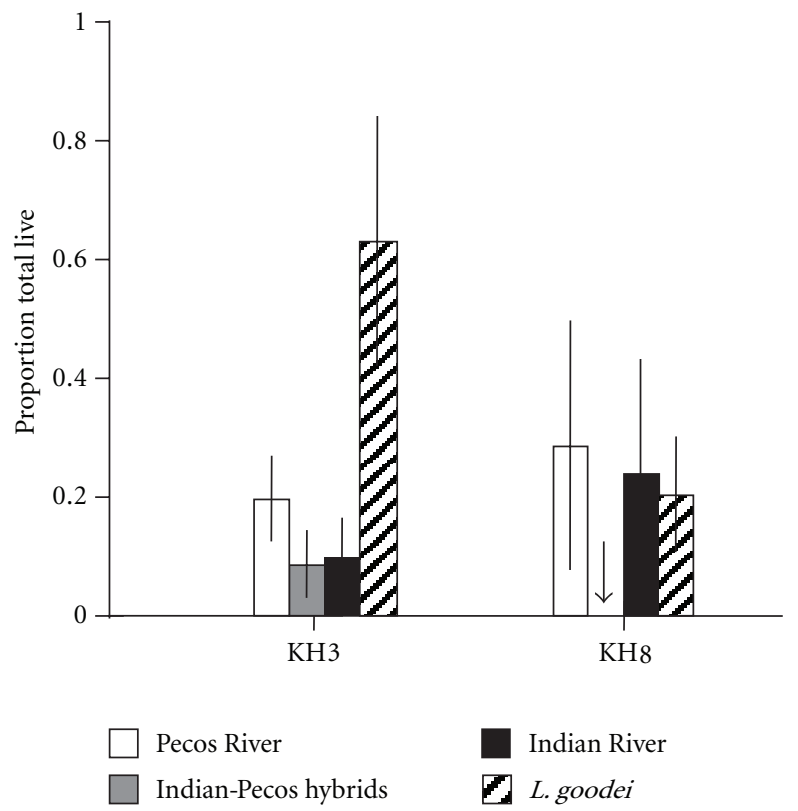

(c)

Figure 4: L. parva and L. goodei survival differences in fresh water. Mean survival probabilities ( \pm standard error) for Pecos River (white bars), Indian River (black bars), Indian-Pecos hybrids (gray bars), and L. goodei (hatched bars) crosses in soft (KH3) and hard fresh water (KH8). All crosses were raised in the absence of methylene blue. Arrows indicate mean survival probability of zero. (a) The proportion of eggs hatched, (b) proportion of fry that survived to 14 days after hatch, (c) total survival (proportion of eggs that survived to 14 days after hatch).

occur in the same habitat (such as phytophagous insects [6668]). Nevertheless, some incipient species do show prezygotic isolation without any postzygotic barriers $[57,69,70]$.

There is another possible route to speciation. Genetic divergence might produce hybrid inviability between populations and prezygotic isolation evolves subsequently as divergence continues or as incipient species come into sympatry and reinforcement occurs [18]. When natural selection drives genetic divergence between populations, evolving postzygotic isolation should be primarily environmentally dependent. Many examples of adaptation to divergent environments producing extrinsic isolation exist $[1,4,15,17,19,71-73]$, while there are few examples for intrinsic isolation. In a survey of 20 ecologically divergent species pairs, all species exhibited some prezygotic isolation and extrinsic postzygotic isolation, but only three pairs had any documented intrinsic postzygotic isolation [57]. Intrinsic isolation as a result of ecological divergence has only been substantially documented in dwarf and normal lake whitefish [74, 75], copper tolerant plants [58], and an experimental evolution study in yeast [26]. However, few studies distinguish between extrinsic inviability and intrinsic 
inviability that appears under stressful conditions [62], such as the decreased viability that appeared in challenging water chemistries in our study. Therefore, future work needs to establish the contribution to divergence of both extrinsic and intrinsic postzygotic isolation and the underlying genetic basis of both. Such work will allow us to determine how postzygotic isolation evolves as a consequence of adaptation, the relative importance of extrinsic and intrinsic barriers, and how postzygotic isolation may act alone or in concert with prezygotic isolation to cause ecological speciation.

\section{Acknowledgments}

This work was funded by the University of Illinois and National Science Foundation Grants (DEB 0953716 and IOS $0445127)$ to B. Fuller. B. Colon was supported by an NSF REU Supplemental Award (IOS 0940999). L. Noa provided substantial help with experiments. E. Berdan and D. Welsh assisted with fish collection. This work was approved by the University of Illinois IACUC (Protocol nos. 08183 and 09306). E. Berdan, K. Sawamura, and two anonymous reviewers provided helpful comments on the paper.

\section{References}

[1] D. Schluter, "Ecology and the origin of species," Trends in Ecology and Evolution, vol. 16, no. 7, pp. 372-380, 2001.

[2] H. D. Rundle and P. Nosil, "Ecological speciation," Ecology Letters, vol. 8, no. 3, pp. 336-352, 2005.

[3] D. J. Funk, P. Nosil, and W. J. Etges, "Ecological divergence exhibits consistently positive associations with reproductive isolation across disparate taxa," Proceedings of the National Academy of Sciences of the United States of America, vol. 103, no. 9, pp. 3209-3213, 2006.

[4] D. Schluter, "Evidence for ecological speciation and its alternative," Science, vol. 323, no. 5915, pp. 737-741, 2009.

[5] P. Nosil, L. J. Harmon, and O. Seehausen, "Ecological explanations for (incomplete) speciation," Trends in Ecology and Evolution, vol. 24, no. 3, pp. 145-156, 2009.

[6] J. M. Sobel, G. F. Chen, L. R. Watt, and D. W. Schemske, "The biology of speciation," Evolution, vol. 64, no. 2, pp. 295-315, 2010.

[7] D. W. Schemske and H. D. Bradshaw, "Pollinator preference and the evolution of floral traits in monkeyflowers (Mimulus)," Proceedings of the National Academy of Sciences of the United States of America, vol. 96, no. 21, pp. 11910-11915, 1999.

[8] H. D. Rundle, L. Nagel, J. W. Boughman, and D. Schluter, "Natural selection and parallel speciation in sympatric sticklebacks," Science, vol. 287, no. 5451, pp. 306-308, 2000.

[9] J. W. Boughman, "Divergent sexual selection enhances reproductive isolation in sticklebacks," Nature, vol. 411, no. 6840, pp. 944-948, 2001.

[10] J. W. Boughman, "How sensory drive can promote speciation," Trends in Ecology and Evolution, vol. 17, no. 12, pp. 571-577, 2002.

[11] O. Seehausen, Y. Terai, I. S. Magalhaes et al., "Speciation through sensory drive in cichlid fish," Nature, vol. 455, no. 7213, pp. 620-626, 2008.

[12] M. E. Maan and O. Seehausen, "Ecology, sexual selection and speciation," Ecology Letters, vol. 14, no. 6, pp. 591-602, 2011.
[13] D. Schluter, "Adaptive radiation in sticklebacks: size, shape, and habitat use efficiency," Ecology, vol. 74, no. 3, pp. 699-709, 1993.

[14] D. Schluter, "Adaptive radiation in sticklebacks: trade-offs in feeding performance and growth," Ecology, vol. 76, no. 1, pp. 82-90, 1995.

[15] H. D. Rundle, "A test of ecologically dependent postmating isolation between sympatric sticklebacks," Evolution, vol. 56, no. 2, pp. 322-329, 2002.

[16] M. L. Forister, "Independent inheritance of preference and performance in hybrids between host races of Mitoura butterflies (Lepidoptera: Lycaenidae)," Evolution, vol. 59, no. 5, pp. 1149-1155, 2005.

[17] C. S. Mcbride and M. C. Singer, "Field studies reveal strong postmating isolation between ecologically divergent butterfly populations," PLoS Biology, vol. 8, no. 10, Article ID e1000529, 2010.

[18] T. Dobzhansky, Genetics and the Origin of Species, Columbia University Press, New York, NY, USA, 1937.

[19] D. Schluter and G. L. Conte, "Genetics and ecological speciation," Proceedings of the National Academy of Sciences of the United States of America, vol. 106, supplement 1, pp. 99559962, 2009.

[20] D. C. Presgraves, "The molecular evolutionary basis of species formation," Nature Reviews Genetics, vol. 11, no. 3, pp. 175$180,2010$.

[21] R. E. Naisbit, C. D. Jiggins, M. Linares, C. Salazar, and J. Mallet, "Hybrid sterility, Haldane's rule and speciation in Heliconius cydno and H. melpomene," Genetics, vol. 161, no. 4, pp. 15171526, 2002.

[22] S. Sun, C. T. Ting, and C. I. Wu, "The normal function of a speciation gene, Odysseus, and its hybrid sterility effect," Science, vol. 305, no. 5680, pp. 81-83, 2004.

[23] B. M. Fitzpatrick, "Dobzhansky-Muller model of hybrid dysfunction supported by poor burst-speed performance in hybrid tiger salamanders," Journal of Evolutionary Biology, vol. 21, no. 1, pp. 342-351, 2008.

[24] H. A. Orr and M. Turelli, "The evolution of postzygotic isolation: accumulating Dobzhansky-Muller incompatibilities," Evolution, vol. 55, no. 6, pp. 1085-1094, 2001.

[25] D. C. Presgraves, L. Balagopalan, S. M. Abmayr, and H. A. Orr, "Adaptive evolution drives divergence of a hybrid inviability gene between two species of Drosophila," Nature, vol. 423, no. 6941, pp. 715-719, 2003.

[26] J. R. Dettman, C. Sirjusingh, L. M. Kohn, and J. B. Anderson, "Incipient speciation by divergent adaptation and antagonistic epistasis in yeast," Nature, vol. 447, no. 7144, pp. 585-588, 2007.

[27] J. Ramsey, H. D. Bradshaw, and D. W. Schemske, "Components of reproductive isolation between the monkeyflowers Mimulus lewisii and M. cardinalis (Phrymaceae)," Evolution, vol. 57, no. 7, pp. 1520-1534, 2003.

[28] A. P. Hendry, "Ecological speciation! Or the lack thereof?" Canadian Journal of Fisheries and Aquatic Sciences, vol. 66, no. 8, pp. 1383-1398, 2009.

[29] J. A. Coyne and H. A. Orr, "Patterns of speciation in Drosophila," Evolution, vol. 43, no. 2, pp. 362-381, 1989.

[30] J. A. Coyne and H. A. Orr, "Patterns of speciation in Drosophila revisited," Evolution, vol. 51, no. 1, pp. 295-303, 1997.

[31] T. D. Price and M. M. Bouvier, "The evolution of F1 postzygotic incompatibilities in birds," Evolution, vol. 56, no. 10, pp. 2083-2089, 2002. 
[32] B. M. Fitzpatrick, "Rates of evolution of hybrid inviability in birds and mammals," Evolution, vol. 58, no. 8, pp. 1865-1870, 2004.

[33] D. I. Bolnick and T. J. Near, "Tempo of hybrid inviability in centrarchid fishes (Teleostei: Centrarchidae)," Evolution, vol. 59, no. 8, pp. 1754-1767, 2005.

[34] R. B. Stelkens, K. A. Young, and O. Seehausen, "The accumulation of reproductive incompatibilities in African cichlid fish," Evolution, vol. 64, no. 3, pp. 617-633, 2010.

[35] T. C. Mendelson, "Sexual isolation evolves faster than hybrid inviability in a diverse and sexually dimorphic genus of fish (Percidae: Etheostoma)," Evolution, vol. 57, no. 2, pp. 317-327, 2003.

[36] T. C. Mendelson, V. E. Imhoff, and J. J. Venditti, "The accumulation of reproductive barriers during speciation: postmating barriers in two behaviorally isolated species of darters (Percidae: Etheostoma)," Evolution, vol. 61, no. 11, pp. 2596-2606, 2007.

[37] J. Kitano, S. Mori, and C. L. Peichel, "Phenotypic divergence and reproductive isolation between sympatric forms of Japanese threespine sticklebacks," Biological Journal of the Linnean Society, vol. 91, no. 4, pp. 671-685, 2007.

[38] A. P. Hendry, D. I. Bolnick, D. Berner, and C. L. Peichel, "Along the speciation continuum in sticklebacks," Journal of Fish Biology, vol. 75, no. 8, pp. 2000-2036, 2009.

[39] C. L. Hubbs and R. R. Miller, "Studies of cyprionodont fishes XXII. Variation in Lucania parva, its establishment in the western United States, and description of a new species from an interior basin in Coahuila, Mexico," Miscellaneous Publications, Museum of Zoology, University of Michigan, vol. 127, pp. 1-116, 1965.

[40] R. C. Fuller and L. A. Noa, "Distribution and stability of sympatric populations of Lucania goodei and L parva across Florida," Copeia, no. 3, pp. 699-707, 2008.

[41] R. C. Fuller, K. E. Mcghee, and M. Schrader, "Speciation in killifish and the role of salt tolerance," Journal of Evolutionary Biology, vol. 20, no. 5, pp. 1962-1975, 2007.

[42] R. C. Fuller, "A test for a trade-off in salinity tolerance in early life-history stages in Lucania goodei and L. parva," Copeia, no. 1, pp. 154-157, 2008.

[43] R. C. Fuller, "Genetic incompatibilities in killifish and the role of environment," Evolution, vol. 62, no. 12, pp. 3056-3068, 2008.

[44] L. Khoo, "Fungal diseases in fish," Seminars in Avian and Exotic Pet Medicine, vol. 9, no. 2, pp. 102-111, 2000.

[45] D. H. Evans, P. M. Piermarini, and W. T. W. Potts, "Ionic transport in the fish gill epithelium," Journal of Experimental Zoology, vol. 283, no. 7, pp. 641-652, 1999.

[46] S. Varsamos, C. Nebel, and G. Charmantier, "Ontogeny of osmoregulation in postembryonic fish: a review," Comparative Biochemistry and Physiology Part A, vol. 141, no. 4, pp. 401429, 2005.

[47] G. R. Scott, J. T. Rogers, J. G. Richards, C. M. Wood, and P. M. Schulte, "Intraspecific divergence of ionoregulatory physiology in the euryhaline teleost Fundulus heteroclitus: possible mechanisms of freshwater adaptation," Journal of Experimental Biology, vol. 207, no. 19, pp. 3399-3410, 2004.

[48] A. Whitehead, J. L. Roach, S. Zhang, and F. Galvez, "Genomic mechanisms of evolved physiological plasticity in killifish distributed along an environmental salinity gradient," Proceedings of the National Academy of Sciences of the United States of America, vol. 108, no. 15, pp. 6193-6198, 2011.
[49] G. W. Linam and L. J. Kleinsasser, "Relationship between fishes and water quality in the Pecos River, Texas," River Studies Report, vol. 9, pp. 1-11, 1996.

[50] T. M. Schreier, J. J. Rach, and G. E. Howe, "Efficacy of formalin, hydrogen peroxide, and sodium chloride on fungalinfected rainbow trout eggs," Aquaculture, vol. 140, no. 4, pp. 323-331, 1996.

[51] H. J. Muller, "Isolating mechanisms, evolution and temperature," Biological Symposia, vol. 6, pp. 71-125, 1942.

[52] M. Nei, T. Maruyama, and C. Wu, "Models of evolution of reproductive isolation," Genetics, vol. 103, no. 3, pp. 557-579, 1983.

[53] H. A. Orr, "The population genetics of speciation: the evolution of hybrid incompatibilities," Genetics, vol. 139, no. 4, pp. 1805-1813, 1995.

[54] C. S. Willett, "The nature of interactions that contribute to postzygotic reproductive isolation in hybrid copepods," Genetica, vol. 139, no. 4, pp. 1805-1813, 2011.

[55] N. A. Johnson, "Hybrid incompatibility genes: remnants of a genomic battlefield?" Trends in Genetics, vol. 26, no. 7, pp. 317-325, 2010.

[56] D. A. Williams, S. D. Brown, and D. L. Crawford, "Contemporary and historical influences on the genetic structure of the estuarine-dependent Gulf killifish Fundulus grandis," Marine Ecology Progress Series, vol. 373, pp. 111-121, 2008.

[57] N. L. Chamberlain, R. I. Hill, D. D. Kapan, L. E. Gilbert, and M. R. Kronforst, "Polymorphic butterfly reveals the missing link in ecological speciation," Science, vol. 326, no. 5954, pp. 847-850, 2009.

[58] M. R. Macnair and P. Christie, "Reproductive isolation as a pleiotropic effect of copper tolerance in Mimulus guttatus," Heredity, vol. 50, no. 3, pp. 295-302, 1983.

[59] M. Tobler, R. Riesch, C. M. Tobler, T. Schulz-Mirbach, and M. Plath, "Natural and sexual selection against immigrants maintains differentiation among micro-allopatric populations," Journal of Evolutionary Biology, vol. 22, no. 11, pp. 2298-2304, 2009.

[60] M. Plath, B. Hermann, C. Schröder et al., "Locally adapted fish populations maintain small-scale genetic differentiation despite perturbation by a catastrophic flood event," $B M C$ Evolutionary Biology, vol. 10, no. 1, article 256, 2010.

[61] R. Riesch, M. Plath, and I. Schlupp, "Toxic hydrogen sulphide and dark caves: pronounced male life-history divergence among locally adapted Poecilia mexicana (Poeciliidae)," Journal of Evolutionary Biology, vol. 24, no. 3, pp. 596-606, 2011.

[62] J. A. Coyne and H. A. Orr, Speciation, Sinauer Associations, Sunderland, Mass, USA, 2004.

[63] D. W. Schemske, "Adaptation and the origin of species," American Naturalist, vol. 176, no. 1, pp. S4-S25, 2010.

[64] M. R. Servedio and M. A. F. Noor, "The role of reinforcement in speciation: theory and data," Annual Review of Ecology, Evolution, and Systematics, vol. 34, pp. 339-364, 2003.

[65] S. R. Pryke and S. C. Griffith, "Postzygotic genetic incompatibility between sympatric color morphs," Evolution, vol. 63, no. 3, pp. 793-798, 2009.

[66] S. Via, "Reproductive isolation between sympatric races of pea aphids. I. Gene flow restriction and habitat choice," Evolution, vol. 53, no. 5, pp. 1446-1457, 1999.

[67] H. R. Dambroski, C. Linn, S. H. Berlocher, A. A. Forbes, W. Roelofs, and J. L. Feder, "The genetic basis for fruit odor discrimination in Rhagoletis flies and its significance for sympatric host shifts," Evolution, vol. 59, no. 9, pp. 1953-1964, 2005. 
[68] P. Nosil, "Divergent host plant adaptation and reproductive isolation between ecotypes of Timema cristinae walking sticks," American Naturalist, vol. 169, no. 2, pp. 151-162, 2007.

[69] U. Schliewen, K. Rassmann, M. Markmann, J. Markert, T. Kocher, and D. Tautz, "Genetic and ecological divergence of a monophyletic cichlid species pair under fully sympatric conditions in Lake Ejagham, Cameroon," Molecular Ecology, vol. 10, no. 6, pp. 1471-1488, 2001.

[70] S. K. Huber, L. F. De León, A. P. Hendry, E. Bermingham, and J. Podos, "Reproductive isolation of sympatric morphs in a population of Darwin's finches," Proceedings of the Royal Society B, vol. 274, no. 1619, pp. 1709-1714, 2007.

[71] S. Via, A. C. Bouck, and S. Skillman, "Reproductive isolation between divergent races of pea aphids on two hosts. II. Selection against migrants and hybrids in the parental environments," Evolution, vol. 54, no. 5, pp. 1626-1637, 2000.

[72] D. D. Kapan, "Three-butterfly system provides a field test of Müllerian mimicry," Nature, vol. 409, no. 6818, pp. 338-340, 2001.

[73] J. M. Bono and T. A. Markow, "Post-zygotic isolation in cactophilic Drosophila: larval viability and adult life-history traits of D. mojavensis/D. arizonae hybrids," Journal of Evolutionary Biology, vol. 22, no. 7, pp. 1387-1395, 2009.

[74] G. Lu and L. Bernatchez, "Experimental evidence for reduced hybrid viability between dwarf and normal ecotypes of lake whitefish (Coregonus clupeaformis Mitchill)," Proceedings of the Royal Society B, vol. 265, no. 1400, pp. 1025-1030, 1998.

[75] S. M. Rogers and L. Bernatchez, "The genetic basis of intrinsic and extrinsic post-zygotic reproductive isolation jointly promoting speciation in the lake whitefish species complex (Coregonus clupeaformis)," Journal of Evolutionary Biology, vol. 19, no. 6, pp. 1979-1994, 2006. 

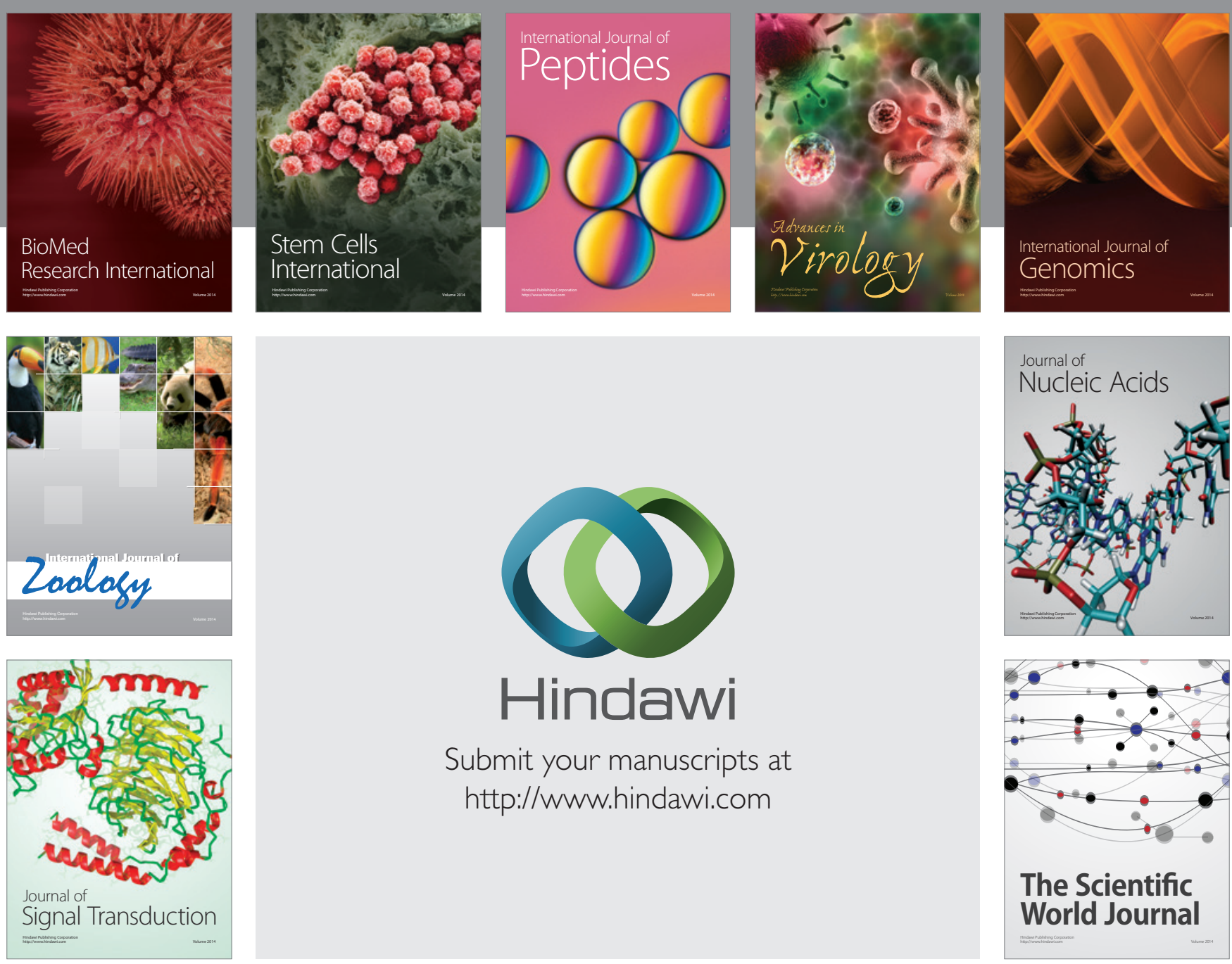

Submit your manuscripts at

http://www.hindawi.com
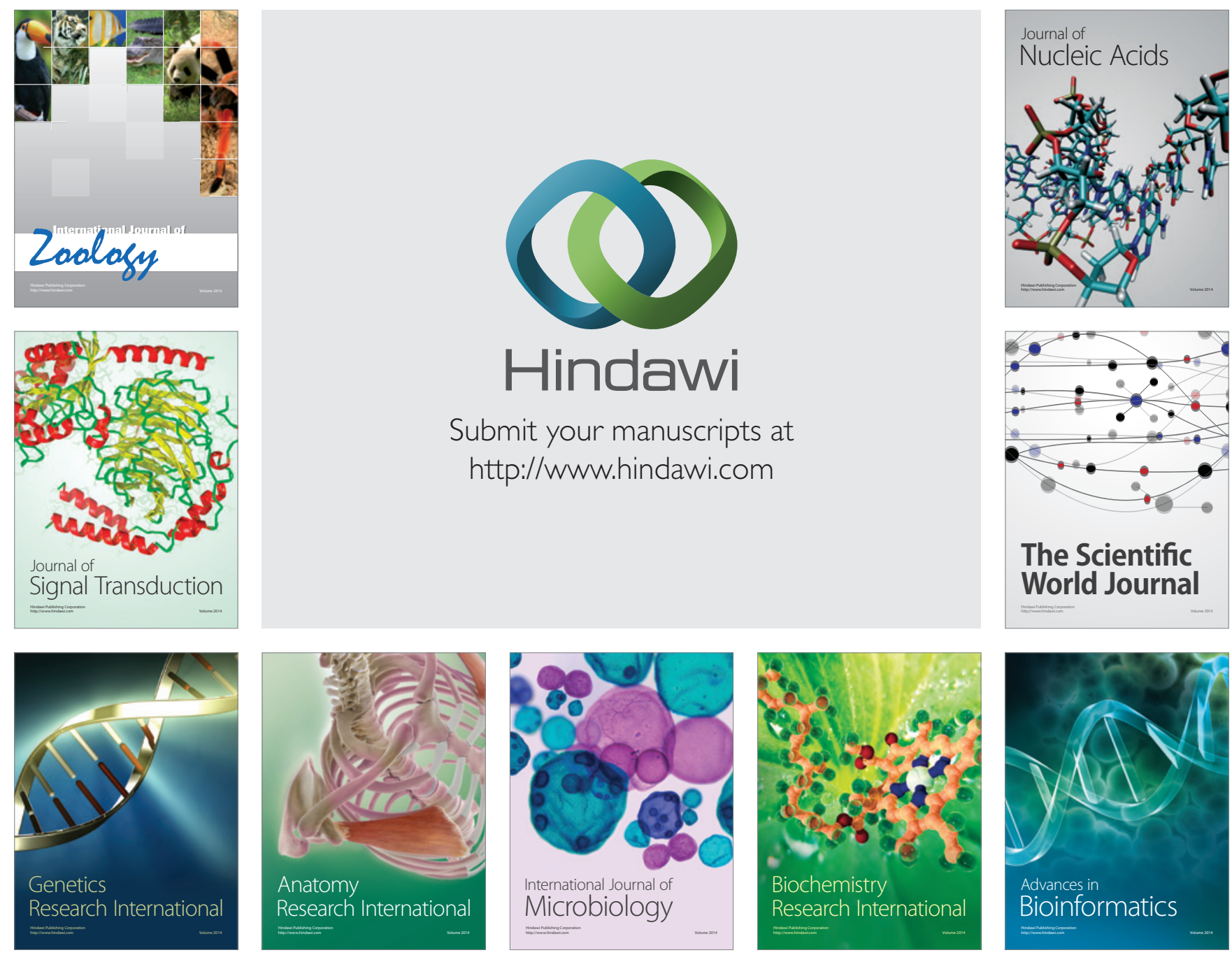

The Scientific World Journal
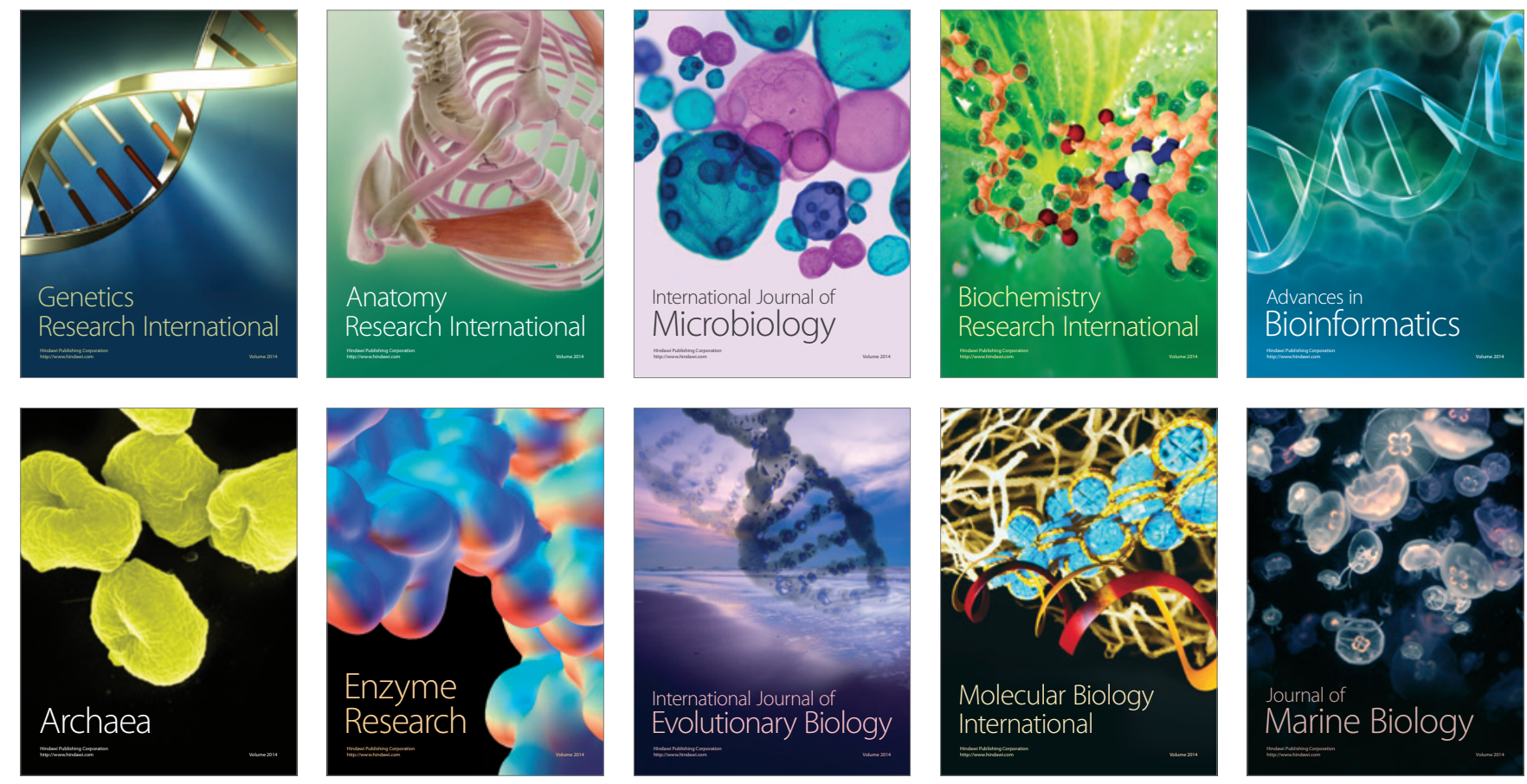